\title{
Association Between Visceral Fat Accumulation and Exercise Tolerance in Non-Obese Subjects Without Diabetes
}

\author{
Miki Shioya-Yamada a , Kazunori Shimada, b, c, e, Miho Nishitani-Yokoyama ${ }^{\mathrm{b}}$, Eiryu Sai ${ }^{\mathrm{b}}$, \\ Kageumi Takeno ${ }^{\text {d }}$, Yoshifumi Tamura ${ }^{\text {c, d }}$, Hirotaka Watada ${ }^{c, d}$, Ryuzo Kawamoric, d, \\ Hiroyuki Daida ${ }^{\text {b, c }}$, Sachio Kawai ${ }^{a}$
}

\begin{abstract}
Background: We examined the associations between visceral fat accumulation, presence of the components of metabolic syndrome (MetS), and exercise tolerance in non-obese subjects without diabetes.

Methods: Seventy-four non-obese, non-diabetic Japanese men were enrolled. The subjects were divided into the following two groups: non-obese subjects without any MetS risk factors $(\mathrm{n}=38$, Group A) and non-obese subjects with one or two MetS risk factors $(n=36$, Group B). Anthropometric and metabolic parameters were measured. The response of heart rate (HR) and blood pressure (BP), and exercise tolerance were also evaluated with a cardiopulmonary exercise test using a bicycle ergometer.

Results: The body mass index, abdominal circumference, visceral fat area, and homeostasis model assessment-insulin resistance, were significantly higher, while levels of anaerobic threshold and maximal oxygen uptake were significantly lower in Group B than in Group A. The levels of resting HR, resting $\mathrm{BP}$, and $\mathrm{BP}$ at maximal exercise were significantly higher in Group B than in Group A. There were no significant differences in the HR at maximal exercise as well as the HR and BP after exercise between the two groups. The visceral fat area was significantly and negatively correlated with exercise tolerance. Multivariate linear regression analyses demonstrated that visceral fat area, but not abdominal circumference, was significantly and independently associated with maximal oxygen uptake.
\end{abstract}

Manuscript submitted May 9, 2018, accepted June 4, 2018

aJuntendo University Graduate School of Health and Sports Science, Chiba, Japan

bDepartment of Cardiovascular Medicine, Juntendo University Graduate School of Medicine, Tokyo, Japan

${ }^{\text {'S }}$ portology Center, Juntendo University Graduate School of Medicine, Tokyo, Japan

${ }^{\mathrm{d}}$ Department of Metabolism and Endocrinology, Juntendo University Graduate School of Medicine, Tokyo, Japan

${ }^{\mathrm{e} C}$ Corresponding Author: Kazunori Shimada, Department of Cardiovascular Medicine, Juntendo University Graduate School of Medicine, 2-1-1, Hongo, Bunkyo-ku, Tokyo 113-8421, Japan. Email: shimakaz@juntendo.ac.jp

doi: https://doi.org/10.14740/jocmr3403w
Conclusions: These data suggest that the visceral fat area is a significant determinant for exercise tolerance even in non-obese subjects without diabetes.

Keywords: Exercise tolerance; Visceral fat; Metabolic syndrome; Non-obese men

\section{Introduction}

Metabolic syndrome (MetS), defined as a combination of at least two metabolic abnormalities, in addition to central adiposity, including hyperglycemia, dyslipidemia, and hypertension, is implicated as a risk factor for the onset of type 2 diabetes and/or atherosclerotic disease $[1,2]$. According to the World Health Organization criteria, insulin resistance is considered a major pathology that contributes to MetS [3]. In addition, considerable epidemiological and physiological evidence suggests that obesity, particularly the accumulation of visceral adipose tissue, is an important factor for metabolic risk and insulin resistance [4]. In Japan, the reported prevalence of MetS among diabetic subjects is $50 \%$ in men and $30 \%$ in women [5]. Obesity-related insulin resistance is a powerful risk factor for the onset of type 2 diabetes and a precursor of MetS; it is recognized as the root cause for the progression of atherosclerosis.

In Caucasians, the prevalence of obesity is high among those with diabetes and/or cardiovascular disease. However, many individuals with an Asian origin, including those with a Japanese origin [6], who have diabetes or atherosclerosis, have a body mass index (BMI) $<25 \mathrm{~kg} / \mathrm{m}^{2}$, and are classified as normal weight. In addition, approximately $80 \%$ of cardiovascular disease mortality is accounted for by non-obese patients (BMI $<25 \mathrm{~kg} / \mathrm{m}^{2}$ ) [7]. The pathophysiology of diabetes and atherosclerosis in non-obese Asians, including the Japanese, remains unclear. Thus, it is crucial to determine the pathological significance in non-obese individuals, including the relationship between metabolic abnormalities and exercise tolerance [8].

Patients with a high tolerance for exercise and physical activities typically have a relatively lower visceral fat area. Reduced exercise tolerance is a known independent factor for the onset of MetS $[9,10]$. Furthermore, moderate or higher- 
Table 1. Characteristics of Each Group

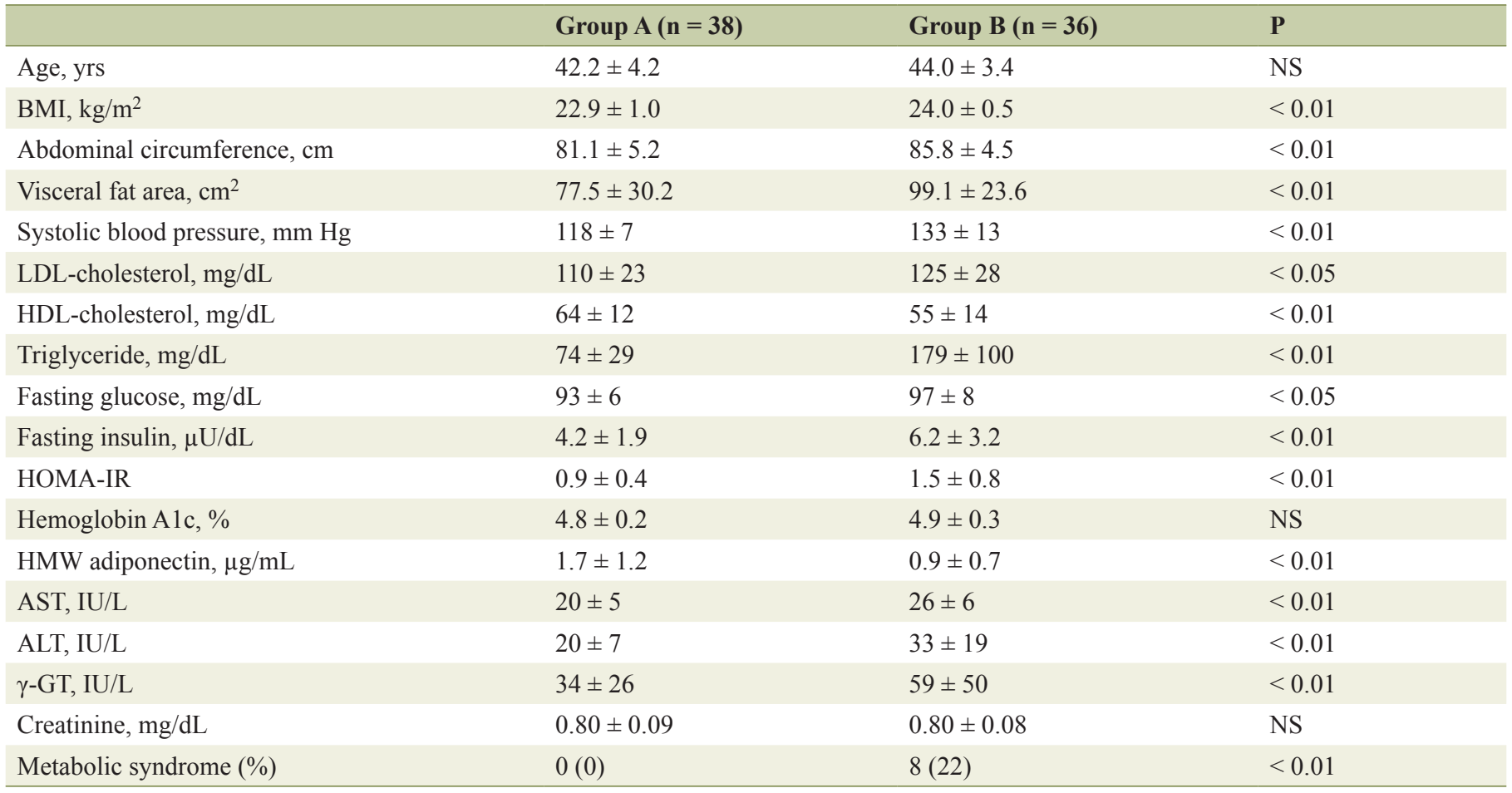

Data are presented as the mean value \pm SD. BMI: body mass index; LDL: low-density lipoprotein; HDL: high-density lipoprotein; HOMA-IR: homeostasis model assessment-insulin resistance; HMW adiponectin: high molecular weight adiponectin; AST: aspartate transaminase; ALT: alanine aminotransferase; GT: glutamyltranspeptidase.

intensity physical activity is known to reduce visceral fat and reduce the risk of MetS or minimize its severity $[11,12]$. In addition, recent studies have demonstrated that MetS is associated with heart rate (HR) [13] and blood pressure (BP) response during and after exercise [14]. However, to our knowledge, no studies have investigated the impact of the presence of MetS components on HR and BP response during and after exercise in non-obese individuals without diabetes.

Therefore, we investigated the associations between exercise tolerance and factors related to MetS in non-obese subjects who did not have diabetes.

\section{Methods}

\section{Subjects}

Japanese men aged 30 - 50 years who did not have diabetes were enrolled for the Sportology Center Core Study through poster announcements at major companies and internet advertisements $[15,16]$. Subjects, who were undergoing treatment for hypertension, lipid disorders, diabetes, cardiovascular disease, chronic lung disease, cancer, renal failure, or serious hepatic dysfunction, were excluded. We also performed a $75-\mathrm{g}$ oral glucose tolerance test to rule out diabetes at the baseline screening. We initially enrolled 98 Japanese men who did not have diabetes and whose BMI was $21 \mathrm{~kg} / \mathrm{m}^{2}$ to $24.9 \mathrm{~kg} / \mathrm{m}^{2}$.
To assess the parameters of the cardiopulmonary exercise test using a bicycle ergometer, we excluded 24 subjects for whom complete data regarding BP and HR during and after exercise testing were unavailable. Finally, we enrolled 74 non-obese men without diabetes in this study. All the subjects gave written informed consent for study participation. This study was approved by the ethics committee of the institute and was conducted as per the principles in the Declaration of Helsinki.

Based on the definition of MetS in Japan [15], we defined the following three cardiometabolic risk factors: hyperglycemia (fasting plasma glucose level $\geq 110 \mathrm{mg} / \mathrm{dL}$ ), dyslipidemia (triglycerides $\geq 150 \mathrm{mg} / \mathrm{dL}$ and/or high-density lipoprotein (HDL)-cholesterol $<40 \mathrm{mg} / \mathrm{dL}$ ), and hypertension (systolic $\mathrm{BP} \geq 130 \mathrm{~mm} \mathrm{Hg}$ and/or diastolic $\mathrm{BP} \geq 85 \mathrm{~mm} \mathrm{Hg}$ ) in addition to high abdominal circumference ( $\geq 85 \mathrm{~cm}$ for men). The subjects were then divided into the following two groups: subjects without any MetS risk factors $(\mathrm{n}=38$, Group A) and those with one or two MetS risk factors ( $\mathrm{n}=36$, Group B).

\section{Measurements}

Body height, body weight, and abdominal circumference were measured for each subject. Magnetic resonance imaging of the abdomen was performed at the level of the navel to consistently quantify the visceral fat area [17]. The subjects fasted for $10 \mathrm{~h}$, and blood samples were collected early in the morning. Laboratory examinations were conducted to measure the com- 
Table 2. Comparison of Parameters of Cardiopulmonary Exercise Test in Each Group

\begin{tabular}{|c|c|c|c|}
\hline & Group A $(n=38)$ & Group B $(n=36)$ & $\mathbf{P}$ \\
\hline HR at rest, bpm & $74 \pm 13$ & $79 \pm 11$ & $<0.05$ \\
\hline $\mathrm{HR}$ at maximal exercise, bpm & $173 \pm 14$ & $169 \pm 15$ & NS \\
\hline $\mathrm{HR}$ at $3 \mathrm{~min}$ after exercise, bpm & $121 \pm 12$ & $114 \pm 14$ & NS \\
\hline HR at $5 \mathrm{~min}$ after exercise, bpm & $108 \pm 13$ & $100 \pm 21$ & NS \\
\hline $\mathrm{BP}$ at $1 \mathrm{~min}$ after exercise, $\mathrm{mm} \mathrm{Hg}$ & $172 \pm 22$ & $178 \pm 34$ & NS \\
\hline $\mathrm{BP}$ at $3 \mathrm{~min}$ after exercise, $\mathrm{mm} \mathrm{Hg}$ & $165 \pm 13$ & $177 \pm 37$ & NS \\
\hline $\mathrm{BP}$ at $5 \mathrm{~min}$ after exercise, $\mathrm{mm} \mathrm{Hg}$ & $137 \pm 19$ & $147 \pm 26$ & NS \\
\hline Anaerobic threshold, $\mathrm{mL} / \mathrm{kg} / \mathrm{min}$ & $20.0 \pm 6.1$ & $16.3 \pm 3.8$ & $<0.01$ \\
\hline
\end{tabular}

Data are presented as the mean value \pm SD. HR: heart rate; BP: blood pressure.

plete blood cell count, low-density lipoprotein (LDL)-cholesterol, HDL-cholesterol, triglyceride, blood glucose, insulin, glycosylated hemoglobin (HbAlc), high-molecular weight (HMW) adiponectin, aspartate transaminase (AST), alanine aminotransferase (ALT), gamma-glutamyltranspeptidase $(\gamma$ GT), and creatinine levels. Homeostasis model assessment-insulin resistance (HOMA-IR) was calculated using the fasting insulin and fasting glucose concentrations.

Exercise tolerance was evaluated using a cardiopulmonary exercise test with a bicycle ergometer (Corival 400, Lobe B.V., Groningen, Netherlands). Exercise was started at a workload (W) of $40 \mathrm{~W}$, and the load (ramp) was gradually increased at a rate of $15 \mathrm{~W} / \mathrm{min}$. BP and HR were measured at rest, during exercise when the peak value was attained, and during recovery phases at 1,3 , and 5 min after the exercise. An expiratory gas analysis machine (Vmax-295, Sensor Medics Co., Yorba Linda, CA, USA) was used to measure the anaerobic threshold (AT) and maximal oxygen uptake. The AT point was determined using the "V-slope" method, as previously described [18].

\section{Statistical analyses}

Results are expressed as mean \pm standard deviation values. The significance levels were calculated using the Chi-square test and Fisher's exact test for non-continuous variables and Student's $t$-test for continuous variables. The relationship of maximum oxygen uptake, visceral fat area, and other risk factors was assessed using Pearson's correlation co-efficient, as appropriate. Multivariable linear regression analysis was performed to determine the relationship of exercise tolerance with the demographic characteristics and clinical data of the patients. In a multiple regression model, a standardized partial regression coefficient $(\beta)$ is the slope coefficient; this $\beta$ value has the advantage of being comparable between independent variables because the unit of measurement is eliminated. JMP12 (for Windows, SAS Institute, Cary, NC) was used for the statistical analyses, and P-values $<0.05$ were considered statistically significant.

\section{Results}

\section{Characteristics of the study subjects}

The mean age of the 74 subjects was $43.1 \pm 3.8$ years and was not significantly different between the two groups (Table 1). The BMI levels of Group B were significantly higher than those of Group A $\left(24.0 \pm 0.5\right.$ vs. $\left.22.9 \pm 1.0 \mathrm{~kg} / \mathrm{m}^{2}, \mathrm{P}<0.01\right)$. The abdominal circumference $(85.8 \pm 4.5$ vs. $81.1 \pm 5.2 \mathrm{~cm}, \mathrm{P}$ $<0.01)$, visceral fat area $\left(99.1 \pm 23.6\right.$ vs. $77.5 \pm 30.2 \mathrm{~cm}^{2}, \mathrm{P}$ $<0.01)$, systolic BP $(133 \pm 13$ vs. $118 \pm 7 \mathrm{mmHg}, \mathrm{P}<0.01)$, LDL-cholesterol $(125 \pm 28$ vs. $110 \pm 23 \mathrm{mg} / \mathrm{dL}, \mathrm{P}<0.05)$, triglycerides ( $179 \pm 100$ vs. $74 \pm 29 \mathrm{mg} / \mathrm{dL}, \mathrm{P}<0.01)$, fasting glucose $(97 \pm 8$ vs. $93 \pm 6 \mathrm{mg} / \mathrm{dL}, \mathrm{P}<0.01)$, fasting insulin $(6.2 \pm 3.2$ vs. $4.2 \pm 1.9 \mu \mathrm{U} / \mathrm{dL}, \mathrm{P}<0.01)$, HOMA-IR $(1.5 \pm 0.8$ vs. $0.9 \pm 0.4 \mathrm{mg} / \mathrm{dL}, \mathrm{P}<0.01)$, AST $(26 \pm 6$ vs. $20 \pm 5 \mathrm{IU} / \mathrm{L}$, $\mathrm{P}<0.01)$, ALT $(33 \pm 19$ vs. $20 \pm 7 \mathrm{IU} / \mathrm{L}, \mathrm{P}<0.01)$, and $\gamma-\mathrm{GT}$ $(59 \pm 50$ vs. $34 \pm 26 \mathrm{IU} / \mathrm{L}, \mathrm{P}<0.01)$ were significantly higher in Group B than in Group A. The levels of HDL-cholesterol $(55 \pm 14$ vs. $64 \pm 12 \mathrm{mg} / \mathrm{dL}, \mathrm{P}<0.01)$ and HMW adiponectin $(0.9 \pm 0.7$ vs. $1.7 \pm 1.2 \mu \mathrm{g} / \mathrm{mL}, \mathrm{P}<0.01)$ were significantly lower in Group B than in Group A. The prevalence of MetS was significantly higher in Group B than in Group A (22\% vs. $0 \%, \mathrm{P}<0.01)$.

\section{Exercise tolerance}

The levels of resting HR (79 \pm 11 vs. $74 \pm 13$ bpm, $\mathrm{P}<0.05)$, resting $\mathrm{BP}(136 \pm 10$ vs. $124 \pm 11 \mathrm{~mm} \mathrm{Hg}, \mathrm{P}<0.01)$, and $\mathrm{BP}$ at maximal exercise $(223 \pm 22$ vs. $205 \pm 21 \mathrm{~mm} \mathrm{Hg}, \mathrm{P}<0.01)$ were significantly higher in Group B than in Group A (Table 2 ). There were no significant differences in the HR at maximal 
Table 3. Multiple Linear Regression Analysis of Factors on Exercise Tolerance in Non-Obese Subjects

\begin{tabular}{lll}
\hline & $\boldsymbol{\beta}$ & P \\
\hline Body mass index, $\mathrm{kg} / \mathrm{m}^{2}$ & 0.01 & $\mathrm{NS}$ \\
Visceral fat area, $\mathrm{cm}^{2}$ & -0.26 & 0.04 \\
Triglyceride, $\mathrm{mg} / \mathrm{dL}$ & -0.22 & $\mathrm{NS}$ \\
HDL-cholesterol, $\mathrm{mg} / \mathrm{dL}$ & 0.08 & $\mathrm{NS}$ \\
LDL-cholesterol, $\mathrm{mg} / \mathrm{dL}$ & -0.08 & $\mathrm{NS}$ \\
HOMA-IR & -0.01 & $\mathrm{NS}$ \\
ALT, IU/L & -0.01 & $\mathrm{NS}$ \\
HMW adiponectin, $\mu \mathrm{g} / \mathrm{mL}$ & 0.02 & $\mathrm{NS}$ \\
\hline
\end{tabular}

HDL: high-density lipoprotein; LDL: low-density lipoprotein; HOMA-IR homeostasis model assessment-nsulin resistance; ALT: alanine aminotransferase; HMW adiponectin: high molecular weight adiponectin.

exercise or in the HR and BP after exercise between the two groups.

The levels of AT $(16.3 \pm 3.8$ vs. $20.1 \pm 6.1 \mathrm{~mL} / \mathrm{kg} / \mathrm{min}, \mathrm{P}$ $<0.01)$ and maximal oxygen uptake $(30.5 \pm 5.7$ vs. $35.4 \pm 7.1$ $\mathrm{mL} / \mathrm{kg} / \mathrm{min}, \mathrm{P}<0.01$ ) were significantly lower in Group B than in Group A (Table 2).

In all the 74 non-obese subjects, there was a significant negative correlation between the visceral fat area and exercise tolerance $(\mathrm{r}=-0.37, \mathrm{P}<0.01)$ (Fig. 1). The abdominal circumference highly and positively correlated with the visceral fat area. In addition, the levels of AST, ALT, and $\gamma$-GT were also highly and positively correlated with each value. Therefore, we performed multivariable linear regression analysis as follows. In a multivariate analysis including BMI, visceral fat area, triglycerides, HDL-cholesterol, LDL-cholesterol, fasting glucose, HOMA-IR, AST, and HMW adiponectin, only visceral fat area was significantly associated with exercise toler-

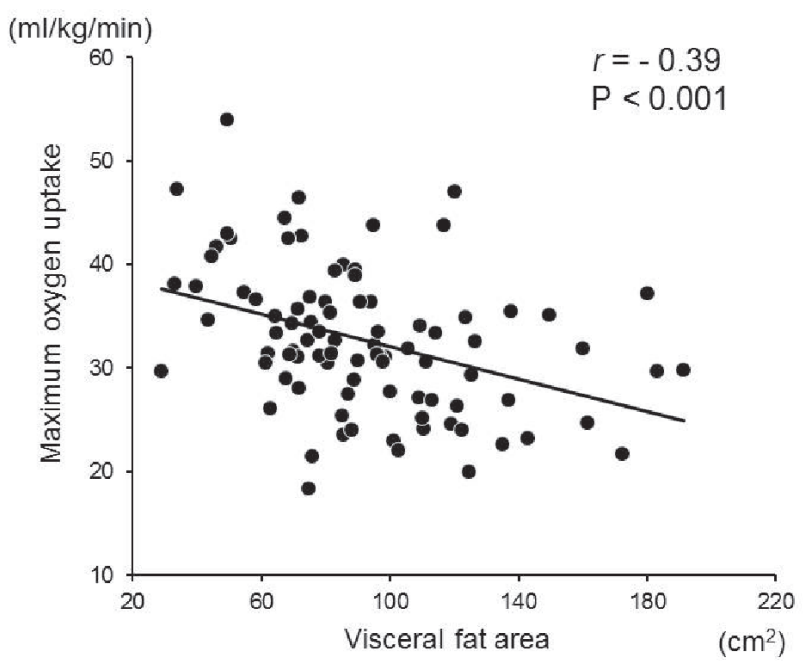

Figure 1. Correlation between the visceral fat area and maximum oxygen uptake. A significant inverse relationship was observed between the visceral fat area and maximum oxygen uptake in the non-obese subjects $(r=-0.37, P<0.01, n=74)$.
Table 4. Multiple Linear Regression Analysis of Factors on Exercise Tolerance in Non-Obese Subjects

\begin{tabular}{lll}
\hline & $\boldsymbol{\beta}$ & P \\
\hline Body mass index, $\mathrm{kg} / \mathrm{m}^{2}$ & 0.02 & $\mathrm{NS}$ \\
Abdominal circumference, $\mathrm{cm}^{2}$ & -0.21 & $\mathrm{NS}$ \\
Triglyceride, $\mathrm{mg} / \mathrm{dL}$ & -0.23 & $\mathrm{NS}$ \\
HDL-cholesterol, $\mathrm{mg} / \mathrm{dL}$ & 0.08 & $\mathrm{NS}$ \\
LDL-cholesterol, $\mathrm{mg} / \mathrm{dL}$ & -0.08 & $\mathrm{NS}$ \\
HOMA-IR & -0.01 & $\mathrm{NS}$ \\
ALT, IU/L & -0.02 & $\mathrm{NS}$ \\
HMW adiponectin, $\mu \mathrm{g} / \mathrm{mL}$ & 0.04 & $\mathrm{NS}$ \\
\hline
\end{tabular}

ance $(\beta=-0.26, \mathrm{P}=0.04)$ (Table 3$)$. However, multivariate analysis including BMI, abdominal circumference, BP at rest, $\mathrm{BP}$ at maximal exercise, triglycerides, HDL-C, fasting glucose, HOMA-IR, AST, and HMW adiponectin, showed that no significant independent factors were associated with exercise tolerance (Table 4).

\section{Discussion}

The present study showed that abdominal circumference and visceral fat area were higher, while AT and maximal oxygen uptake were lower in Group B (non-obese subjects with one or two MetS risk factors) than in Group A (non-obese subjects without any MetS risk factors). In addition, the visceral fat area was a significant determinant for exercise tolerance even in non-obese subjects without diabetes.

Previous studies have reported an association between visceral fat and exercise tolerance [19-21]. In Japanese patients with impaired glucose tolerance and diabetes, the levels of cardiorespiratory fitness were associated with metabolic abnormalities, including visceral fat area [19]. In first-degree blood relatives of individuals with type 2 diabetes, increased visceral fat accumulation and reduced maximal oxygen uptake were observed compared to that in subjects without a family history of diabetes [20]. People without diabetes but with low cardiorespiratory fitness had a significantly higher visceral fat than those with high cardiorespiratory fitness [21]. These previous studies included people with obesity and/or diabetes. Therefore, to our knowledge, the present study is the first report to demonstrate an association between visceral fat accumulation and exercise tolerance in non-obese subjects without diabetes.

In the present study, a multivariate analysis showed that only visceral fat area was a significant factor associated with exercise tolerance. The precise underlying mechanism by which excess abdominal fat accumulation leads to exercise intolerance remains unclear. Nyholm et al reported that both visceral adiposity and reduced aerobic fitness were strongly associated with insulin resistance [20]. Usui et al also demonstrated that abdominal fat accumulation was a significant factor for insulin resistance [21]. Insulin resistance is associated with the increased secretion of tumor necrosis factor alpha $(\mathrm{TNF}-\alpha)$ and free fatty acids, as well as decreased secretion 
of adiponectin from the visceral adipose tissue [22]. Elevated levels of TNF- $\alpha$ are reportedly associated with reduced skeletal muscle strength and exercise capacity [23]. In addition, TNF- $\alpha$ may mediate the down-regulation of peroxisome proliferator-activated receptor gamma coactivator- $1 \alpha$, resulting in impaired skeletal muscle function [24]. These mechanisms could impair exercise tolerance via vascular endothelial and skeletal muscle dysfunction. It has been recently reported that abdominal obesity is associated with an increased risk of mortality in patients with heart failure with preserved ejection fraction (HFpEF) [25, 26]. HFpEF patients frequently present with coexisting MetS and have a high systemic proinflammatory state that leads to myocardial inflammation and fibrosis, oxidative stress, and alterations in the cardiomyocyte signaling pathways. These alterations promote microvascular and cardiac dysfunction $[25,26]$. In fact, a reduction in the visceral adipose tissue was independently related to an improvement in the cardiometabolic risk profile and cardiorespiratory fitness [27].

In most Asian countries, the mean BMI of patients with diabetes ranges from $20 \mathrm{~kg} / \mathrm{m}^{2}$ to $25 \mathrm{~kg} / \mathrm{m}^{2}$ [6]. Furthermore, MetS commonly develops in Asians with a normal BMI, as compared to that in BMI-matched non-Hispanic Caucasians and African Americans [7]. A recent position statement from the American Diabetes Association revised the recommended BMI cutoff for screening Asian American type 2 diabetes from $25 \mathrm{~kg} / \mathrm{m}^{2}$ to $23 \mathrm{~kg} / \mathrm{m}^{2}[28,29]$. We recently reported that muscle insulin resistance is present in Japanese men with even one cardiometabolic risk factor and a BMI of $23 \mathrm{~kg} / \mathrm{m}^{2}$ to $25 \mathrm{~kg} /$ $\mathrm{m}^{2}$ [15]. Therefore, the threshold of tissue-specific insulin resistance in an Asian population may be a BMI that falls in the range of $23 \mathrm{~kg} / \mathrm{m}^{2}$ to $25 \mathrm{~kg} / \mathrm{m}^{2}$.

Rest exercise transition and exercise recovery transitions reflect changes in the combinations of parasympathetic withdrawal and sympathetic activation and parasympathetic nervous system reactivation, respectively [30,31]. Cardiovascular abnormalities and aberrations in these transitions have been reported in patients with obesity/overweight [32] and diabetes [33]. A high resting HR in subjects with insulin resistance is thought to serve as a compensatory mechanism adopted to maintain the cardiac output in response to a lower stroke volume $[13,33]$. In the present study, significant differences in the resting $\mathrm{BP}$ and $\mathrm{BP}$ at maximal exercise, but not in the $\mathrm{BP}$ after exercise, were observed between the two groups. In addition, there were no significant differences in the HR at maximal exercise and during exercise between the two groups. The present study enrolled non-obese subjects without diabetes. This could be the reason for the lack of significant differences in the BP levels of the two groups in the recovery phase after exercise testing.

The present study had certain limitations. First, this study had a small sample size and employed a cross sectional design. Therefore, we were unable to prove any causal relationships between visceral fat accumulation and exercise tolerance. Second, we did not collect data regarding the proinflammatory mediators, including TNF- $\alpha$. Future studies are warranted to confirm and clarify our findings. Third, we enrolled Japanese men aged between 30 - 50 years who did not have diabetes. Thus, our data has limited generalizability.

\section{Conclusions}

The results of this study suggest that visceral fat area is a significant determinant for exercise tolerance even in non-obese subjects who do not have diabetes. Large-scale prospective studies need to be conducted to confirm and clarify the present findings.

\section{Grant Support}

This work was supported by the High Technology Research Center Grant from the Ministry of Education, Culture, Science and Technology, Japan.

\section{Conflict of Interest}

None declared.

\section{References}

1. The Japan Diabetes Society. Metabolic Syndrome. In: Evidence-based practical guideline for the treatment of diabetes in Japan 2013. Tokyo, Japan. Nankodo Co, 2013: 325-341.

2. Alberti KG, Eckel RH, Grundy SM, Zimmet PZ, Cleeman JI, Donato KA, Fruchart JC, et al. Harmonizing the metabolic syndrome: a joint interim statement of the International Diabetes Federation Task Force on Epidemiology and Prevention; National Heart, Lung, and Blood Institute; American Heart Association; World Heart Federation; International Atherosclerosis Society; and International Association for the Study of Obesity. Circulation. 2009;120(16):1640-1645.

3. Alberti KG, Zimmet PZ. Definition, diagnosis and classification of diabetes mellitus and its complications. Part 1: diagnosis and classification of diabetes mellitus provisional report of a WHO consultation. Diabet Med. 1998;15(7):539-553.

4. Reaven GM. Banting lecture 1988. Role of insulin resistance in human disease. Diabetes. 1988;37(12):15951607.

5. Shimajiri Y, Tsunoda K, Furuta M, Kadoya Y, Yamada S, Nanjo K, Sanke T. Prevalence of metabolic syndrome in Japanese type 2 diabetic patients and its significance for chronic vascular complications. Diabetes Res Clin Pract. 2008;79(2):310-317.

6. Chan JC, Malik V, Jia W, Kadowaki T, Yajnik CS, Yoon KH, Hu FB. Diabetes in Asia: epidemiology, risk factors, and pathophysiology. JAMA. 2009;301(20):2129-2140.

7. Pan WH, Yeh WT, Weng LC. Epidemiology of metabolic syndrome in Asia. Asia Pac J Clin Nutr. 2008;(Suppl 1):37-42.

8. Liu L, Miura K, Fujiyoshi A, Kadota A, Miyagawa N, Nakamura Y, Ohkubo T, et al. Impact of metabolic syndrome on the risk of cardiovascular disease mortality in the Unit- 
ed States and in Japan. Am J Cardiol. 2014;113(1):84-89.

9. LaMonte MJ, Barlow CE, Jurca R, Kampert JB, Church TS, Blair SN. Cardiorespiratory fitness is inversely associated with the incidence of metabolic syndrome: a prospective study of men and women. Circulation. 2005;112(4):505-512.

10. O'Donovan G, Thomas EL, McCarthy JP, Fitzpatrick J, Durighel G, Mehta S, Morin SX, et al. Fat distribution in men of different waist girth, fitness level and exercise habit. Int J Obes (Lond). 2009;33(12):1356-1362.

11. O'Donovan G, Kearney E, Sherwood R, Hillsdon M. Fatness, fitness, and cardiometabolic risk factors in middleaged white men. Metabolism. 2012;61(2):213-220.

12. Irwin ML, Ainsworth BE, Mayer-Davis EJ, Addy CL, Pate RR, Durstine JL. Physical activity and the metabolic syndrome in a tri-ethnic sample of women. Obes Res. 2002;10(10):1030-1037.

13. Silva L, Zamuner AR, Gentil P, Alves FM, Leal AGF, Soares V, Silva MS, et al. Cardiac Autonomic Modulation and the Kinetics of Heart Rate Responses in the On- and Off-Transient during Exercise in Women with Metabolic Syndrome. Front Physiol. 2017;8:542.

14. Dubey P, Tiwari S, Bajpai M, Singh K, Jha P. Effect of Metaboreflex on Cardiovascular System in Subjects of Metabolic Syndrome. J Clin Diagn Res. 2017;11(7):CC01CC04.

15. Takeno K, Tamura Y, Kawaguchi M, Kakehi S, Watanabe T, Funayama T, Furukawa Y, et al. Relation between insulin sensitivity and metabolic abnormalities in Japanese men with BMI of 23-25 kg/m(2). J Clin Endocrinol Metab. 2016;101(10):3676-3684.

16. Kaga H, Tamura Y, Takeno K, Kakehi S, Funayama T, Furukawa Y, Nishitani-Yokoyama M, et al. Correlates of insulin clearance in apparently healthy non-obese Japanese men. Sci Rep. 2017;7(1):1462.

17. Klopfenstein BJ, Kim MS, Krisky CM, Szumowski J, Rooney WD, Purnell JQ. Comparison of 3 T MRI and CT for the measurement of visceral and subcutaneous adipose tissue in humans. Br J Radiol. 2012;85(1018):e826-830.

18. Beaver WL, Wasserman K, Whipp BJ. A new method for detecting anaerobic threshold by gas exchange. J Appl Physiol (1985). 1986;60(6):2020-2027.

19. Nagano M, Kai Y, Zou B, Hatayama T, Suwa M, Sasaki $\mathrm{H}$, Kumagai S. The contribution of cardiorespiratory fitness and visceral fat to risk factors in Japanese patients with impaired glucose tolerance and type 2 diabetes mellitus. Metabolism. 2004;53(5):644-649.

20. Nyholm B, Nielsen MF, Kristensen K, Nielsen S, Ostergard T, Pedersen SB, Christiansen T, et al. Evidence of increased visceral obesity and reduced physical fitness in healthy insulin-resistant first-degree relatives of type 2 diabetic patients. Eur J Endocrinol. 2004;150(2):207-214.
21. Usui C, Asaka M, Kawano H, Aoyama T, Ishijima T, Sakamoto S, Higuchi M. Visceral fat is a strong predictor of insulin resistance regardless of cardiorespiratory fitness in non-diabetic people. J Nutr Sci Vitaminol (Tokyo). 2010;56(2):109-116.

22. Mlinar B, Marc J. New insights into adipose tissue dysfunction in insulin resistance. Clin Chem Lab Med. 2011;49(12):1925-1935.

23. Toth MJ, Ades PA, Tischler MD, Tracy RP, LeWinter MM. Immune activation is associated with reduced skeletal muscle mass and physical function in chronic heart failure. Int J Cardiol. 2006;109(2):179-187.

24. Tang K, Wagner PD, Breen EC. TNF-alpha-mediated reduction in PGC-1alpha may impair skeletal muscle function after cigarette smoke exposure. J Cell Physiol. 2010;222(2):320-327.

25. Obokata M, Borlaug BA. Response by Obokata and Borlaug to Letter Regarding Article, "Role of Diastolic Stress Testing in the Evaluation for Heart Failure With Preserved Ejection Fraction: A Simultaneous Invasive-Echocardiographic Study". Circulation. 2017;136(4):430-431.

26. Tsujimoto T, Kajio H. Abdominal obesity is associated with an increased risk of all-cause mortality in patients with HFpEF. J Am Coll Cardiol. 2017;70(22):2739-2749.

27. Borel AL, Nazare JA, Smith J, Almeras N, Tremblay A, Bergeron J, Poirier P, et al. Visceral and not subcutaneous abdominal adiposity reduction drives the benefits of a 1-year lifestyle modification program. Obesity (Silver Spring). 2012;20(6):1223-1233.

28. Hsu WC, Araneta MR, Kanaya AM, Chiang JL, Fujimoto W. BMI cut points to identify at-risk Asian Americans for type 2 diabetes screening. Diabetes Care. 2015;38(1):150158.

29. Araneta MR, Kanaya AM, Hsu WC, Chang HK, Grandinetti A, Boyko EJ, Hayashi T, et al. Optimum BMI cut points to screen asian americans for type 2 diabetes. Diabetes Care. 2015;38(5):814-820.

30. Mitchell JH. Cardiovascular control during exercise: central and reflex neural mechanisms. Am J Cardiol. 1985;55(10):34D-41D.

31. Arai Y, Saul JP, Albrecht P, Hartley LH, Lilly LS, Cohen RJ, Colucci WS. Modulation of cardiac autonomic activity during and immediately after exercise. Am J Physiol. 1989;256(1 Pt 2):H132-141.

32. Franco RL, Privett SH, Bowen MK, Acevedo EO, Arrowood JA, Wickham EP, Evans RK. Sympathetic activity assessed during exercise recovery in young obese females. J Pediatr. 2015;167(2):378-383 e371.

33. Baldi JC, Wilson GA, Wilson LC, Wilkins GT, Lamberts RR. The type 2 diabetic heart: its role in exercise intolerance and the challenge to find effective exercise interventions. Sports Med. 2016;46(11):1605-1617. 